\title{
Dynamic karyotype evolution and unique sex determination systems in Leptidea wood white butterflies
}

\author{
Jindra Šíchovái,2, Anna Voleníková ${ }^{2}$, Vlad Dincă ${ }^{3,4}$, Petr Nguyen ${ }^{1,2}$, Roger Vila ${ }^{4}$, Ken Sahara ${ }^{5}$ and František Marec ${ }^{1,2^{*}}$
}

\begin{abstract}
Background: Chromosomal rearrangements have the potential to limit the rate and pattern of gene flow within and between species and thus play a direct role in promoting and maintaining speciation. Wood white butterflies of the genus Leptidea are excellent models to study the role of chromosome rearrangements in speciation because they show karyotype variability not only among but also within species. In this work, we investigated genome architecture of three cryptic Leptidea species (L. juvernica, L. sinapis and L. reali) by standard and molecular cytogenetic techniques in order to reveal causes of the karyotype variability.

Results: Chromosome numbers ranged from $2 n=85$ to 91 in $L$. juvernica and $2 n=69$ to 73 in L. sinapis (both from Czech populations) to $2 n=51$ to 55 in L. reali (Spanish population). We observed significant differences in chromosome numbers and localization of cytogenetic markers (rDNA and $\mathrm{H} 3$ histone genes) within the offspring of individual females. Using FISH with the (TTAGG) $n$ telomeric probe we also documented the presence of multiple chromosome fusions and/or fissions and other complex rearrangements. Thus, the intraspecific karyotype variability is likely due to irregular chromosome segregation of multivalent meiotic configurations. The analysis of female meiotic chromosomes by GISH and CGH revealed multiple sex chromosomes: $W_{1} W_{2} W_{3} Z_{1} Z_{2} Z_{3} Z_{4}$ in $L$. juvernica, $W_{1} W_{2} W_{3} Z_{1} Z_{2} Z_{3}$ in $L$. sinapis and $W_{1} W_{2} W_{3} W_{4} Z_{1} Z_{2} Z_{3} Z_{4}$ in $L$. reali.

Conclusions: Our results suggest a dynamic karyotype evolution and point to the role of chromosomal rearrangements in the speciation of Leptidea butterflies. Moreover, our study revealed a curious sex determination system with 3-4 W and 3-4 Z chromosomes, which is unique in the Lepidoptera and which could also have played a role in the speciation process of the three Leptidea species.
\end{abstract}

Keywords: Lepidoptera, Wood white butterflies, Karyotype variability, Fluorescence in situ hybridization Chromosome fusion and fission, Multiple sex chromosomes, Speciation

\section{Background}

Speciation, i.e. the origin of new species, is a complex evolutionary process which leads to the formation of barriers preventing gene flow between emerging species. Defining the factors that generate such barriers is a central goal for evolutionary biologists. Among animals, moths and butterflies (insect order Lepidoptera) represent an ideal model group for the study of various

\footnotetext{
*Correspondence: marec@entu.cas.cz

'Institute of Entomology, Biology Centre CAS, 37005 České Budějovice,

Czech Republic

${ }^{2}$ Faculty of Science, University of South Bohemia, 37005 České Budějovice,

Czech Republic

Full list of author information is available at the end of the article
}

aspects of speciation. This is mainly due to the immense diversity of Lepidoptera, which include nearly 160,000 species and belong to the most speciose groups of animals [1]. Moreover, the study of moths and butterflies provides a number of practical advantages. Many species can be easily collected in the field, reared and hybridized in laboratory conditions and experiments can be replicated fairly often due to the relatively short generation time of many species.

Among traditional models, the Heliconius butterflies have been the subject of a high number of evolutionary studies showing that various wing patterns, resulting from predator-induced selection through Müllerian mimicry, ultimately lead to divergence and speciation 
(e.g. [2-6]). The shift in colour pattern mimicry also played a key role in generating pre-mating isolation as male mate preferences often led to strong assortative mating between individuals with similar wing pattern phenotypes [7]. Swallowtail butterflies of the genus Papilio are another diverse group of Lepidoptera where the evolution of mimicry greatly contributed to their spectacular radiation [8-10]. Lepidoptera also include models for research of sex pheromone communication and its role as a pre-zygotic barrier [11, 12]. A wellknown example is the European corn borer, Ostrinia nubilalis, which comprises two sympatric races that are prevented from mating by utilizing opposite sex pheromone isomers of the same compound [13, 14]. The butterfly subgenus Agrodiaetus is one of the few taxa where reinforcement of pre-zygotic isolation has been demonstrated [15].

It is generally accepted that chromosomal rearrangements have the potential to limit introgression and thus facilitate the development and maintenance of reproductive isolation by means of suppressed recombination [16-18]. Reduced recombination enables the accumulation of genetic incompatibilities and leads to divergence and speciation. Suppression of recombination is an intrinsic feature of sex chromosomes which were suggested to play a disproportionate role in lepidopteran speciation [19, 20]. Recent studies in geographic subspecies of wild silkworms, Samia cynthia ssp. (Saturniidae), suggest that chromosomal rearrangements resulting in multiple sex chromosomes may also contribute to the formation of reproductive barriers and thus promote divergence and eventually speciation [21, 22]. Moreover, the holokinetic nature of lepidopteran chromosomes, i.e. the lack of a distinct primary constriction (the centromere), is expected to facilitate karyotype evolution mainly via chromosomal fusion and fission by reducing the risk of formation of dicentric and acentric chromosomes [23]. However, results of comparative genomics revealed a high degree of conserved synteny of genes between the silkworm Bombyx mori (Bombycoidea) and several other lepidopteran species [24-30]. The extensive conservation of chromosome print across Lepidoptera suggests evolutionary stability of lepidopteran karyotypes, with most of haploid chromosome numbers ranging $n=$ 28-32 [31] and the most common and probably also ancestral number of $\mathrm{n}=31[30,32]$.

The remarkably stable chromosome numbers and highly conserved synteny of genes between chromosomes of distant species contrast with the exceptional diversity of karyotypes found in some lepidopteran taxa. Probably the greatest interspecific karyotype variation in the animal kingdom was found in blue butterflies (Lycaenidae: Polyommatinae) of the genus Polyommatus with haploid chromosome numbers ranging from $n=10$ to $\mathrm{n}=223[15,33-35]$. The latter, observed in the Atlas blue, Polyommatus atlantica, represents the highest chromosome number not only of Lepidoptera but of all animals [36]. In addition, blue butterflies of the subgenus Agrodiaetus represent the group with the largest difference in the number of chromosomes between sister species. Karyotypes of Polyommatus (Agrodiaetus) biruni and $P$. (A.) posthumus consist of $\mathrm{n}=10$ and $\mathrm{n}=90$ elements, respectively, with no intermediate karyomorphs. The similarity in genome size of these closely related species suggests that the karyotype variation is not caused by polyploidy but arose through chromosomal rearrangements such as fusion and fission [37]. However, recent comparative phylogenetic studies found little evidence supporting the role of chromosomal rearrangements in the speciation of Agrodiaetus blues and rather stressed the importance of reinforcement of their prezygotic isolation [15].

Exceptional intraspecific variability of karyotypes was also found in wood white butterflies of the genus Leptidea comprising several Eurasian species [38, 39]. In this genus, chromosome numbers vary greatly between and within species. While two species with predominantly Eastern Palaearctic distribution, L. morsei and L. amurensis, probably have a constant number of chromosomes ( $n=54$ and $n=61$, respectively; [40]), three cryptic species mainly from the Western Palaearctic have a variable number of chromosomes [38, 41]. The most striking case is L. sinapis, which shows a gradual decrease in the diploid chromosome number from $2 \mathrm{n}=106$ in Spain to $2 \mathrm{n}=56$ in eastern Kazakhstan, resulting in a $6000 \mathrm{~km}$ wide chromosomal cline of recent origin [39]. Excluding polyploidy, this is the widest known within-species chromosome number range for any animal or plant. Moreover, a variable number of chromosomes was described in the other two cryptic species, $L$. reali $(2 \mathrm{n}=$ 52-54) and L. juvernica $(2 \mathrm{n}=80-84)$ [38].

Although the nature of dynamic evolution of Leptidea karyotypes and its role in speciation is not yet known, the chromosomal cline found in L. sinapis provided strong evidence for rapid and extensive within-species accumulation of numerous chromosomal rearrangements [39]. While such clinal speciation is theoretically possible, it is difficult to document without further research. In this study, we integrated standard cytogenetic techniques and FISH (fluorescence in situ hybridization) mapping of major ribosomal RNA (rRNA) and H3 histone genes to study among- and within-species variability in the karyotypes of three cryptic Leptidea species (L. juvernica, $L$. sinapis and $L$. reali). We also determined the sex chromosome constitution using genomic in situ hybridization (GISH) and examined molecular differentiation of the sex chromosomes through comparative genomic hybridization (CGH). Cytogenetic 
characteristics were compared with the aim of understanding karyotype and sex chromosome evolution in Leptidea butterflies.

\section{Results}

Molecular identification of Leptidea specimens

Morphometric analysis of genitalia allowed us to identify only two groups, $L$. sinapis and the group consisting of $L$. reali and $L$. juvernica, whose genitalia cannot be reliably distinguished [38]. Phylogenetic analyses based on two DNA markers, the mitochondrial cytochrome $c$ oxidase subunit $1(C O I)$ gene and the nuclear internal transcribed spacer 2 (ITS2) sequence, revealed three supported major clades corresponding to $L$. juvernica, $L$. sinapis and L. reali (Fig. 1 and Additional file 1: Figure S1). Relationships among these clades coincide with previous results $[38,41]$ with $L$. juvernica being sister to the species pair L. sinapis and L. reali.

\section{Karyotype differences in chromosome number and structure}

Chromosome numbers of all three Leptidea species were counted from mitotic metaphase complements prepared from wing imaginal discs of the last instar larvae and stained by means of FISH with (TTAGG) ${ }_{n}$ telomeric probes (tel-FISH) to facilitate identification of individual chromosome elements. In each Leptidea species, several tens of mitotic metaphases were analysed in the progeny of individual females.

Based on repeated counts we found that chromosome numbers differ considerably in all three species studied. Moreover, we observed differences in the number of chromosomes even among the offspring of individual females. We established that, in the population studied, the chromosome number is not fixed and ranges from $2 \mathrm{n}=85$ to 91 in L. juvernica and $2 \mathrm{n}=69$ to 73 in L. sinapis (both from Czech populations) to $2 \mathrm{n}=51$ to 55 in L. reali (Spanish population). Mitotic complements of $L$. juvernica and $L$. sinapis also displayed a higher variability in chromosome size, having mostly middle- or small-sized chromosomes (L. juvernica, Fig. 2a) or a mixture of large- and small-sized chromosomes (L. sinapis, Fig. 3c, d, f), while in $L$. reali we observed larger chromosomes of a similar size (Fig. 2b).

In male meiotic metaphase I (MI) and pachytene complements of all studied species we observed complex chromosomal rearrangements (Fig. 2c, d) and conspicuous heterochromatin blocks highlighted with DAPI (Fig. 2d). However, in female pachytene complements these DAPI-positive blocks did not allow the identification of a sex chromosome bivalent according to the W chromosome, which is usually the only largely heterochromatic element present in lepidopteran karyotypes [42, 43].

\section{Chromosomal location of major rDNA}

FISH with the biotin-labelled $18 \mathrm{~S}$ ribosomal DNA (rDNA) probe combined with the digoxigenin-labelled $(\text { TTAGG })_{n}$ telomeric probe did not reveal any difference in the number of major rDNA clusters in offspring of three $L$. juvernica and three $L$. reali females. In both species, the rDNA probe mapped to two mitotic metaphase chromosomes of a similar size (Fig. 3a, b; for simplification, hybridization signals of the telomeric probe are not shown) and to a single bivalent in the pachytene stage (insets of Fig. 3a, b). This clearly indicates the presence of a single pair of chromosomes, each carrying a cluster of rRNA genes forming a nucleolar organizer region (NOR). However, we found a substantial interspecific difference in the location of rDNA. While the NORbivalent in pachytene nuclei of $L$. juvernica showed the cluster of rRNA genes associated with a large interstitial block of DAPI-positive heterochromatin (inset of Fig. 3a), rDNA occupied a large terminal segment of the NORbivalent in $L$. reali. In the latter species, rDNA was not associated with heterochromatin, which was observed at the opposite end of the NOR-bivalent (inset of Fig. 3b).

In $L$. sinapis, we found intraspecific variability in the number and position of rDNA clusters both within and among the offspring of individual females (Fig. 3c-g; hybridization signals of the telomeric probe are not shown). In mitotic metaphase complements from the offspring of one female the 18S rDNA probe localized four rDNA sites at the ends of four middle-sized chromosomes (Fig. 3c), thus indicating two pairs of NORchromosomes. However, in mitotic metaphases from the offspring of another female we found either two terminal and one interstitial signal (Fig. 3d) or three terminal hybridization signals (Fig. 3f). The difference among siblings was confirmed in pachytene nuclei where we observed two hybridization signals in a trivalent and one in an element of a bivalent that was heterozygous for rDNA (Fig. 3e) or a pair of signals in a small bivalent and one signal in a larger element of another bivalent (Fig. 3g), respectively.

\section{Chromosomal location of $\mathrm{H} 3$ histone genes}

FISH with the H3 histone probe combined with tel-FISH showed constant results only in L. reali. In all examined larvae from progenies of three different females we found one interstitial cluster of $\mathrm{H} 3$ histone genes in a large pachytene bivalent and two clusters in mitotic metaphase complements (Fig. 4a; hybridization signals of the telomeric probe are not shown). In the pachytene bivalent, the H3 cluster was localized next to a small block of DAPIpositive heterochromatin (inset of Fig. 4a).

In $L$. sinapis and $L$. juvernica, we observed intraspecific variability in the number and location of $\mathrm{H} 3$ histone gene clusters both within and among offspring of 


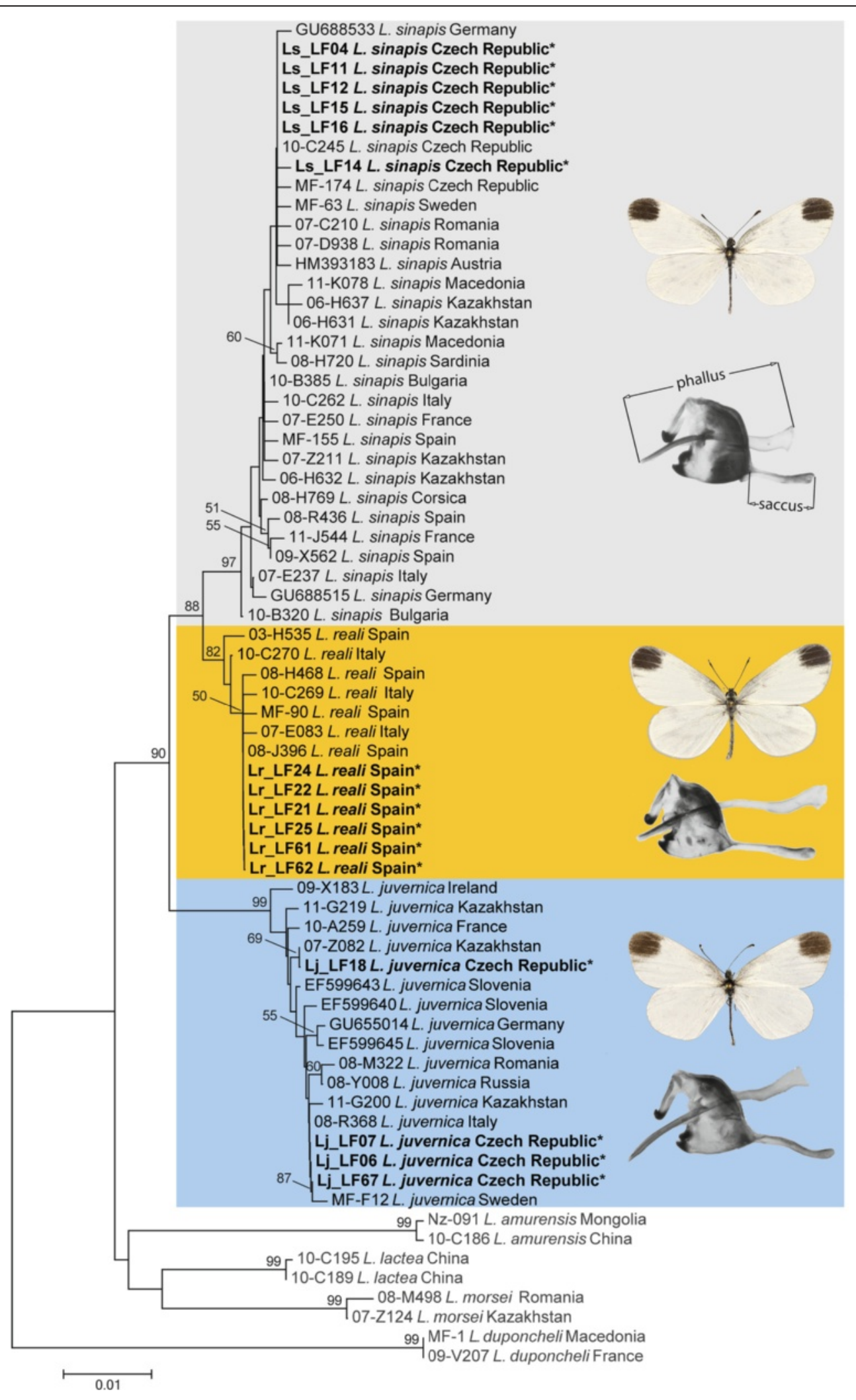

Fig. 1 (See legend on next page.) 
(See figure on previous page.)

Fig. 1 Neighbor-joining tree of mitochondrial COI haplotypes of L. sinapis (grey background), L. reali (orange background) and L. juvernica (blue background). Specimens sequenced and analysed in this study are indicated by an asterisk and were combined with representatives of all available haplotypes of L. sinapis, L. reali and L. juvernica identified in a previous study [41]. Leptidea amurensis, L. lactea, L. morsei and L. duponcheli were used as outgroup. For the origin of all specimens and GenBank accession numbers, see Additional file 5: Table S1. The scale represents 0.01 substitutions per site. Bootstrap supports (100 replicates) are shown next to the recovered nodes. Representative male specimens and genitalia (drawn to scale, with phallus and saccus indicated) are shown
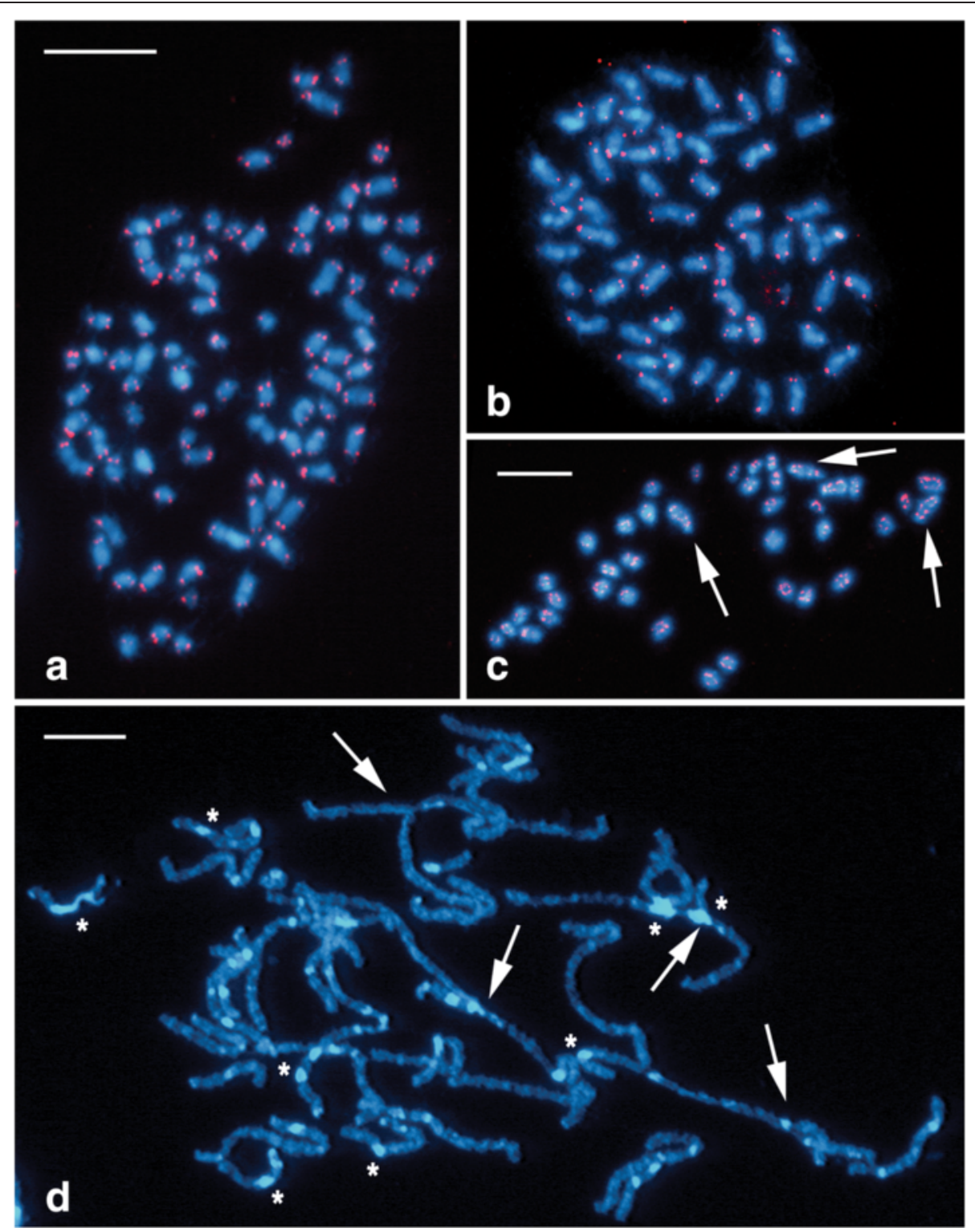

Fig. 2 Karyotype analysis of mitotic and meiotic chromosomes of Leptidea species by FISH with the (TTAGG) $n$ telomeric probe. Hybridization signals of the Cy3-dUTP-labelled telomeric probe (red) indicate chromosome ends in (a-c). Chromosomes were counterstained with DAPI (blue). White arrows indicate chromosome multivalents and asterisks show heterochromatic blocks. a Mitotic metaphase of $L$. juvernica female with numerous middle- or small-sized chromosomes $(2 \mathrm{n}=85)$. b Mitotic metaphase of $L$. reali female with large chromosomes of a similar size $(2 n=55)$. $\mathbf{c}$ Meiotic metaphase I of L. juvernica male showing several chromosome multivalents. $\mathbf{d}$ Meiotic pachytene complement of L. juvernica female showing several chromosome multivalents and numerous blocks of DAPI-highlighted heterochromatin. Scale bars $=10 \mu \mathrm{m} ;$ (a) and (b) have the same scale 


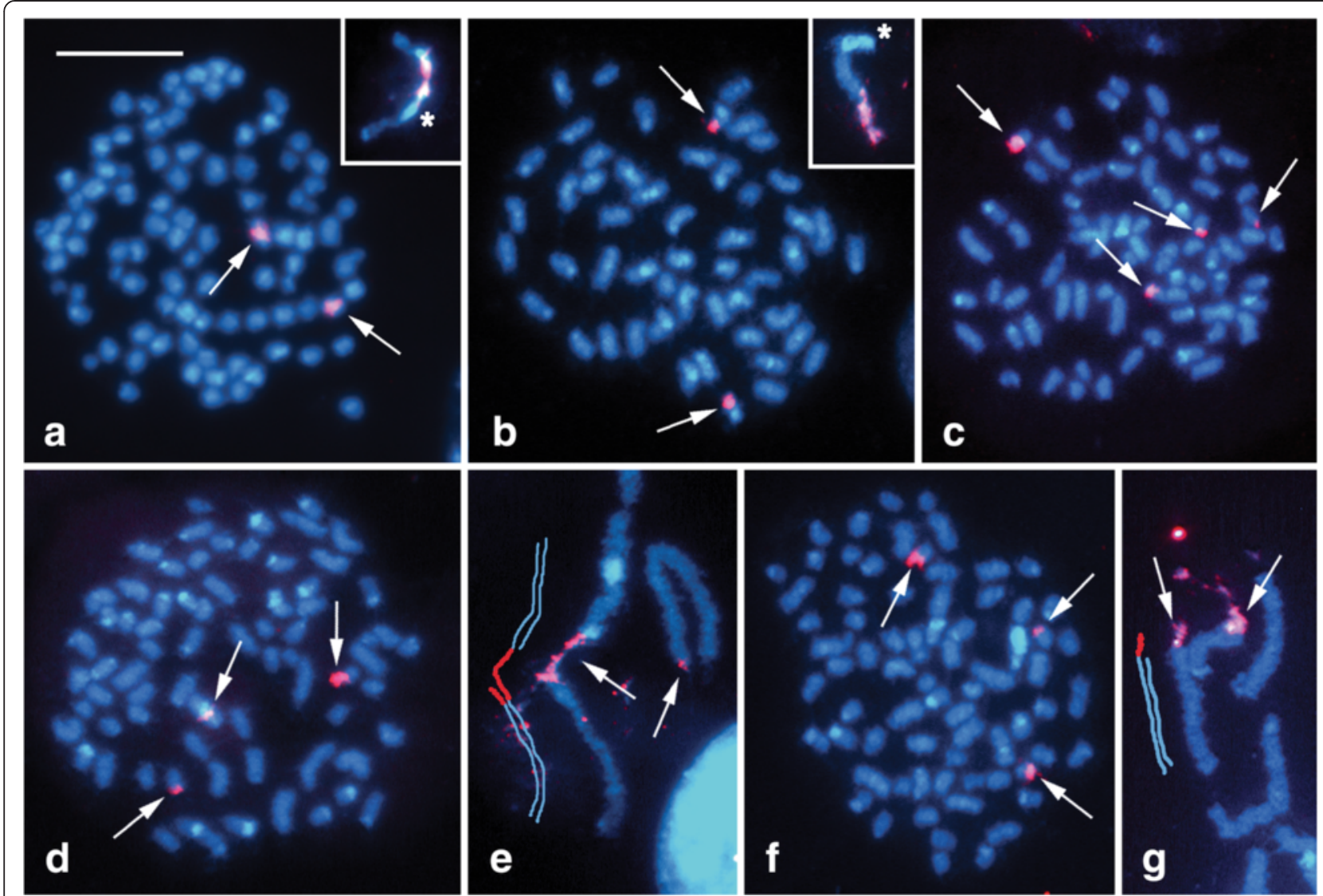

Fig. 3 Localization of rDNA clusters in spread chromosome preparations of three Leptidea species by FISH with 18S rDNA probe. Chromosomes were counterstained with DAPI (blue). Arrows show hybridization signals of the $18 \mathrm{~S}$ rDNA probe (red); asterisks indicate DAPI-positive blocks of heterochromatin. a Mitotic metaphase of L. juvernica male $(2 n=90)$; the inset in the upper right corner shows the pachytene NOR-bivalent with a large interstitial rDNA cluster. $\mathbf{b}$ Mitotic metaphase of $L$. reali female $(2 n=52)$; the inset in the upper right corner shows the pachytene NOR-bivalent with a large terminal rDNA cluster. c Male mitotic metaphase $(2 n=69)$ with a typical hybridization pattern found in the offspring of one $L$. sinapis female. Figures ( $\mathbf{d}-\mathbf{g})$ show a variable pattern in the offspring of another L. sinapis female: (d) mitotic metaphase of male offspring $(2 \mathrm{n}=71)$; (e) hybridization signals on pachytene chromosomes of the same male offspring (schematic drawing shows the structure of a trivalent carrying two out of three rDNA clusters); ( $\mathbf{f})$ mitotic metaphase of female offspring $(2 \mathrm{n}=73)$; $(\mathbf{g})$ hybridization signals on pachytene chromosomes of the same female offspring (schematic drawing shows the structure of a bivalent heterozygous for a terminal rDNA cluster). Scale bar $=10 \mu \mathrm{m}$

individual females (Fig. 4b-i; hybridization signals of the telomeric probe are not shown). In some offspring of one L. sinapis female we observed an interstitial cluster of H3 histone genes in a long pachytene bivalent (inset of Fig. 4b) corresponding to two hybridization signals in a pair of mitotic chromosomes (Fig. 4b) like in L. reali. However, in other offspring of the same female, a single H3 histone gene array mapped to a subterminal region of a short pachytene bivalent (inset of Fig. 4c), corresponding to terminal hybridization signals in a pair of small mitotic chromosomes (Fig. 4c). In the offspring of another L. sinapis female, hybridization signals positioned two $\mathrm{H} 3$ gene clusters to a pachytene trivalent, one terminal in a short chromosome and the other interstitial in a long chromosome (Fig. 4d). In accordance with this hybridization pattern, the $\mathrm{H} 3$ probe identified two mitotic chromosomes, one small and one large (Fig. 4e). In pachytene nuclei of L. juvernica, the $\mathrm{H} 3$ probe hybridized most often to a tetravalent. We found three clusters of hybridization signals, one terminal in a short element and two interstitial in two long elements of the tetravalent (Fig. 4g). The hybridization pattern was confirmed in mitotic nuclei, where the probe mapped $\mathrm{H} 3$ gene arrays to the end of a small chromosome and to the middle of two larger chromosomes (Fig. 4f). The number and location of $\mathrm{H} 3$ gene clusters was characteristic for the offspring of four L. juvernica females. However, in the offspring of another female we found an additional (fourth) H3 gene cluster located at the end of one element of a pachytene bivalent (Fig. 4i), corresponding to a total number of four hybridization signals in mitotic nuclei (Fig. 4h). 


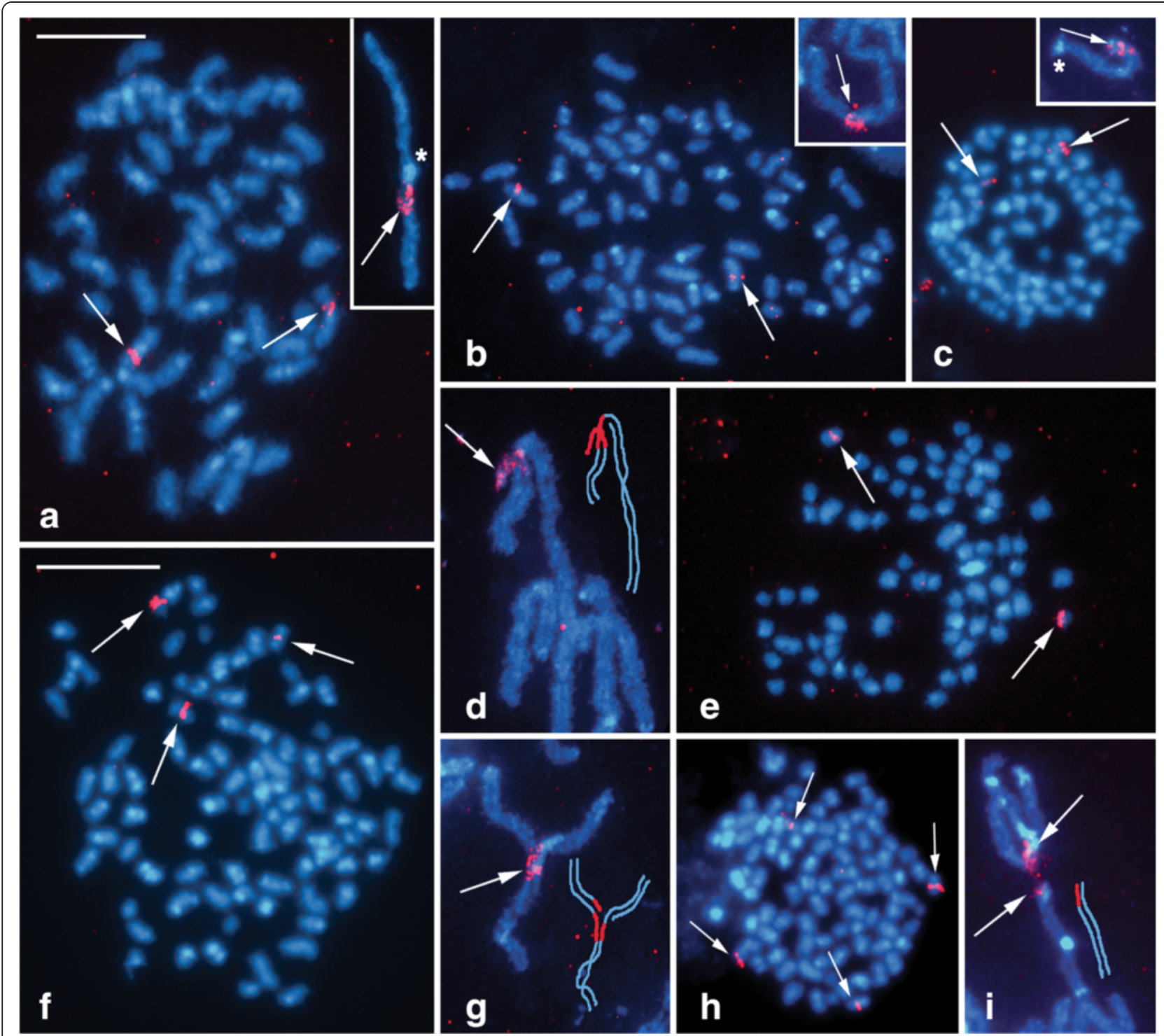

Fig. 4 Localization of H3 histone gene clusters in spread chromosome preparations of three Leptidea species by FISH with H3 gene probe. Chromosomes were counterstained with DAPI (blue). Arrows indicate hybridization signals of the H3 probe (red); asterisks show DAPI-positive blocks of heterochromatin. a Mitotic metaphase of L. reali female; the inset in the upper right corner shows the pachytene $\mathrm{H} 3$ cluster-carrying bivalent. Figures (b-e) show intraspecific variability in the location of H3 histone gene clusters in L. sinapis: (b) mitotic metaphase of male larva; the inset shows the pachytene bivalent carrying a cluster of $\mathrm{H} 3$ genes; (c) mitotic metaphase of another male from the same offspring; the inset shows the pachytene bivalent carrying a cluster of $\mathrm{H} 3$ genes; (d) pachytene trivalent observed in the female offspring of another female (schematic drawing shows the structure of the trivalent and positions of two $\mathrm{H} 3$ clusters); (e) female mitotic metaphase of the same individual. Figures (f-i) show intraspecific variability in the location of $\mathrm{H} 3$ histone gene clusters in L. juvernica: $(\mathbf{f})$ male mitotic metaphase with three hybridization signals, observed in the vast majority of L. juvernica larvae; $(\mathbf{g})$ pachytene tetravalent of the same individual (schematic drawing shows the structure of the tetravalent and positions of three $\mathrm{H3}$ clusters); (h) mitotic metaphase with four hybridization signals found in one male offspring of another female; (i) pachytene tetravalent with three hybridization signals (see schematic drawing in $\mathbf{g}$ ) and bivalent with the fourth hybridization signal located at the end of one homologue. Scale bars $=10 \mu \mathrm{m}$; except for (f) all images have the same scale

\section{Sex chromosome constitution}

We first examined the presence or absence of female specific sex chromatin in polyploid somatic nuclei of all three Leptidea species. The sex chromatin consists of multiple copies of the W chromosome, which usually form one conspicuous heterochromatin body in somatic interphase nuclei of lepidopteran females [44]. In the majority of female larvae of all three species, we observed one larger, more intensely stained heterochromatin body and two tiny indistinct bodies (Additional file 2: Figure S2a). Yet the larger body was much smaller in comparison to the sex chromatin typically observed in 
females of other lepidopteran species $(c f .[45,46])$. In other females we found a variable number of tiny heterochromatin bodies ranging from none to four. Similar findings were made in branched nuclei of adult females with a higher level of ploidy (Additional file 2: Figure $\mathrm{S} 2 \mathrm{~b})$. In the majority of Leptidea males, no sex chromatin was observed in polyploid cells (Additional file 2: Figure S2c). However, in a few male specimens we found a tiny heterochromatin body of uncertain origin (Additional file 2: Figure S2d). The small size and fragmentation of sex chromatin in Leptidea females indicate the presence of interchromosomal rearrangements involving the $\mathrm{W}$ chromosome (see $[42,47])$.

To identify the $\mathrm{W}$ chromosome we examined spread preparations of pachytene oocytes using a combination of GISH and tel-FISH. While GISH differentiated the W chromosome thread in female pachytene nuclei, the telomeric probe helped us to determine chromosomal ends. The female-derived genomic probe also hybridized to heterochromatin blocks on autosomes, which made the identification of the W chromosome more difficult in pachytene nuclei and impossible in mitotic metaphases. Nevertheless, the analysis revealed multiple sex chromosomes in all three Leptidea species with 3-4 W and 3-4 Z chromosomes (Fig. 5a-l; hybridization signals of the telomeric probe are shown in Additional file 3: Figure S3a-l). In $L$. juvernica, we observed a $\mathrm{W}_{1} \mathrm{~W}_{2} \mathrm{~W}_{3} \mathrm{Z}_{1} \mathrm{Z}_{2} \mathrm{Z}_{3} \mathrm{Z}_{4}$ sex chromosome constitution (Fig. 5a-d). While the female genomic DNA (gDNA) probe strongly bound to two W chromosomes, the third one was highlighted only partially (Fig. 5c). Moreover, two of the three $\mathrm{W}$ chromosomes were partially differentiated by DAPI-positive heterochromatin (Fig. 5b, two upper arrows). We found only a small heterochromatin block at the very end of the third W chromosome (Fig. 5b, the lower arrow). In $L$. sinapis, we found a $\mathrm{W}_{1} \mathrm{~W}_{2} \mathrm{~W}_{3} \mathrm{Z}_{1} \mathrm{Z}_{2} \mathrm{Z}_{3}$ sex chromosome system (Fig. 5e-h) with an intensely stained block of heterochromatin on one of the $\mathrm{W}$ chromosomes (Fig. $5 \mathrm{f}$, the middle arrow). We also found a small heterochromatin block at the very end of the smallest $\mathrm{W}$ chromosome (Fig. $5 \mathrm{f}$, the upper arrow) while the third W chromosome was discernible only due to hybridization signals of the female gDNA probe (Fig. $5 \mathrm{~g}$ ). In the third species, $L$. reali, the sex chromosome constitution was $\mathrm{W}_{1} \mathrm{~W}_{2} \mathrm{~W}_{3} \mathrm{~W}_{4} \mathrm{Z}_{1} \mathrm{Z}_{2} \mathrm{Z}_{3} \mathrm{Z}_{4}$ (Fig. 5i-l). Except for the smallest $\mathrm{W}$, the $\mathrm{W}$ chromosomes were highlighted with the female gDNA probe (Fig. 5k), but the staining pattern of DAPI was indistinctive with only few small heterochromatin blocks of higher intensity (Fig. 5j, arrows).

The level of molecular differentiation of the $\mathrm{W}$ and $\mathrm{Z}$ chromosomes was examined using $\mathrm{CGH}$. In pachytene oocytes of the three Leptidea species, the WZ multivalent was discernible from autosomes due to stronger binding of both female- and male-derived probes to the
W chromosomes (Fig. 6a-o). A detailed analysis of the WZ multivalent at the pachytene stage of L. juvernica revealed a similar labelling pattern of both probes (Fig. 6a-e). In L. sinapis, the W chromosomes were decorated with strong but scattered hybridization signals of both genomic probes (Fig. 6f, h, i) with a slight preference for the female probe (Fig. 6h). The highest level of molecular differentiation of the $\mathrm{W}$ and $\mathrm{Z}$ chromosomes was observed in L. reali (Fig. $6 \mathrm{k}-\mathrm{o}$ ), where three out of four W chromosomes were preferentially labelled by the female-derived probe (Fig. $6 \mathrm{~m}$ ). However, the smallest $\mathrm{W}$ chromosome was almost indistinguishable from the $\mathrm{Z}$ chromosome (Fig. 6m-o). Hybridization signals of the male-derived genomic probe were considerably weaker, except for a few intense heterochromatin blocks located on one W chromosome (Fig. 6n).

\section{Discussion}

We performed a detailed karyotype analysis of three cryptic Leptidea species (L. juvernica, L. sinapis and $L$. reali) by means of standard and molecular cytogenetic techniques. Previous studies showed both inter- and intraspecific variation in chromosome numbers in all three studied species. However, the results were based on chromosome counts from squash preparations of metaphase I spermatocytes $[38,39]$, which did not allow the analysis of complex meiotic figures such as multivalents. Using FISH with (TTAGG) ${ }_{n}$ telomeric probes, we confirmed the presence of numerous multivalents in female pachytene nuclei as well as in male pachytene and metaphase I complements in all three species. Detailed analysis of male and female mitotic metaphases prepared from wing imaginal discs allowed us to determine more accurately the range of diploid chromosome numbers that were $2 \mathrm{n}=51-55$ in $L$. reali (Spanish population), $2 \mathrm{n}=69-73$ in L. sinapis and $2 \mathrm{n}=85-91$ in L. juvernica (both Czech populations). These numbers are broadly in line with previous findings $[38,39]$. Nevertheless, we further extended the range of chromosome numbers observed in $L$. juvernica and $L$. reali and provided data from new localities for $L$. juvernica and $L$. sinapis.

Besides inter- and intraspecific karyotype variability, the analysis of mitotic chromosomes allowed us to identify differences in chromosome numbers even within offspring of individual females of all three species. Although such intrapopulation variability could be caused by the presence of supernumerary chromosomes, i.e. B-chromosomes, this scenario was deemed unlikely in the case of Leptidea species [39]. Yet, we cannot totally exclude the involvement of B-chromosomes, especially as they were observed in related white butterflies from the family Pieridae [34]. In wild silkworms (Samia cynthia), chromosomal polymorphism among geographical populations/subspecies was ascribed to repeated autosome-sex chromosome fusions resulting in 

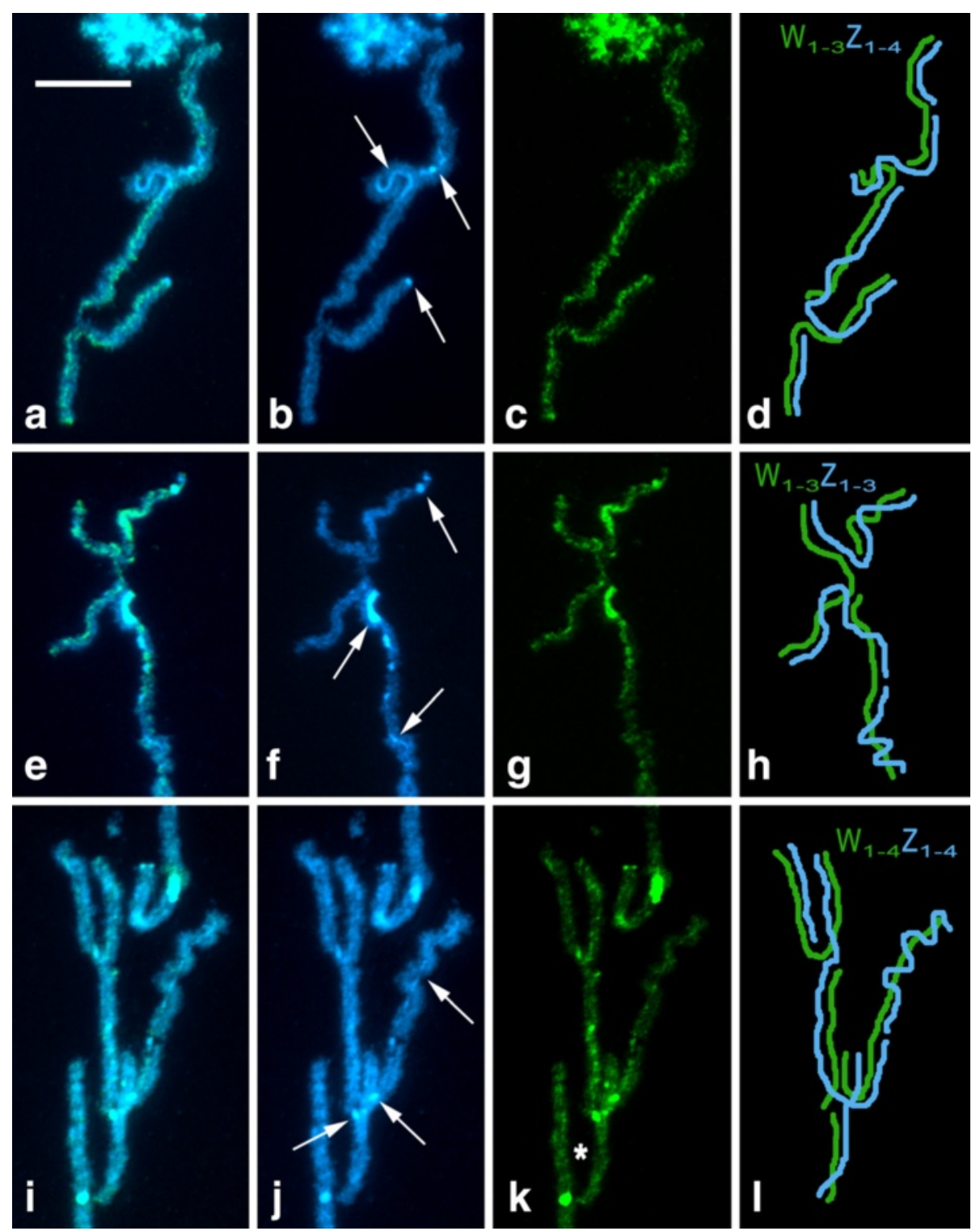

Fig. 5 Genomic in situ hybridization (GISH) in pachytene oocytes of Leptidea juvernica (a-d), L. sinapis (e-h) and L. reali (i-I). Female-derived genomic probes were labelled with fluorescein-12-dUTP (green) and chromosomes were counterstained with DAPI (blue). Figures (a-d), (e-h) and (i-I) show detailed analyses of sex chromosome multivalents $W_{1-n} Z_{1-n}:(\mathbf{a}, \mathbf{e}, \mathbf{i})$ merged images of female genomic probes and DAPI staining; $(\mathbf{b}, \mathbf{f}, \mathbf{j})$ DAPI images; arrows indicate DAPI-positive W-chromosome segments and heterochromatic blocks at the end of the W chromosomes; $(\mathbf{c}, \mathbf{g}, \mathbf{k})$ hybridization pattern of the female genomic probes; the asterisk indicates an undifferentiated segment of one of the W chromosomes; (d, h, I) schematic drawings of the sex chromosome multivalents. Scale bar $=10 \mu \mathrm{m}$

neo-sex chromosomes and reduced chromosome numbers [21]. Similar intraspecific variation resulting in reduced chromosome numbers was also reported in grasshoppers (e.g. [48]) and mammals (e.g. [49, 50]), mainly as a result of Robertsonian translocations. However, karyotype variation observed in the three Leptidea species surpasses previous reports. Our findings, namely the relatively low number of large chromosomes in $L$. reali, variability in chromosome size in the other two species and the occurrence of multivalents in meiotic nuclei of all three species, suggest that the Leptidea karyotypes are differentiated by multiple chromosome fusions and fissions. In addition, our preliminary data showing a similar size of interphase nuclei in the Leptidea species studied (Additional file 4: Figure S4) suggest that their karyotypes did not differentiate through polyploidy. Uneven chromosome segregation of multivalents during meiotic division is thus the most plausible explanation for the intraspecific and intrapopulation karyotype variations. 

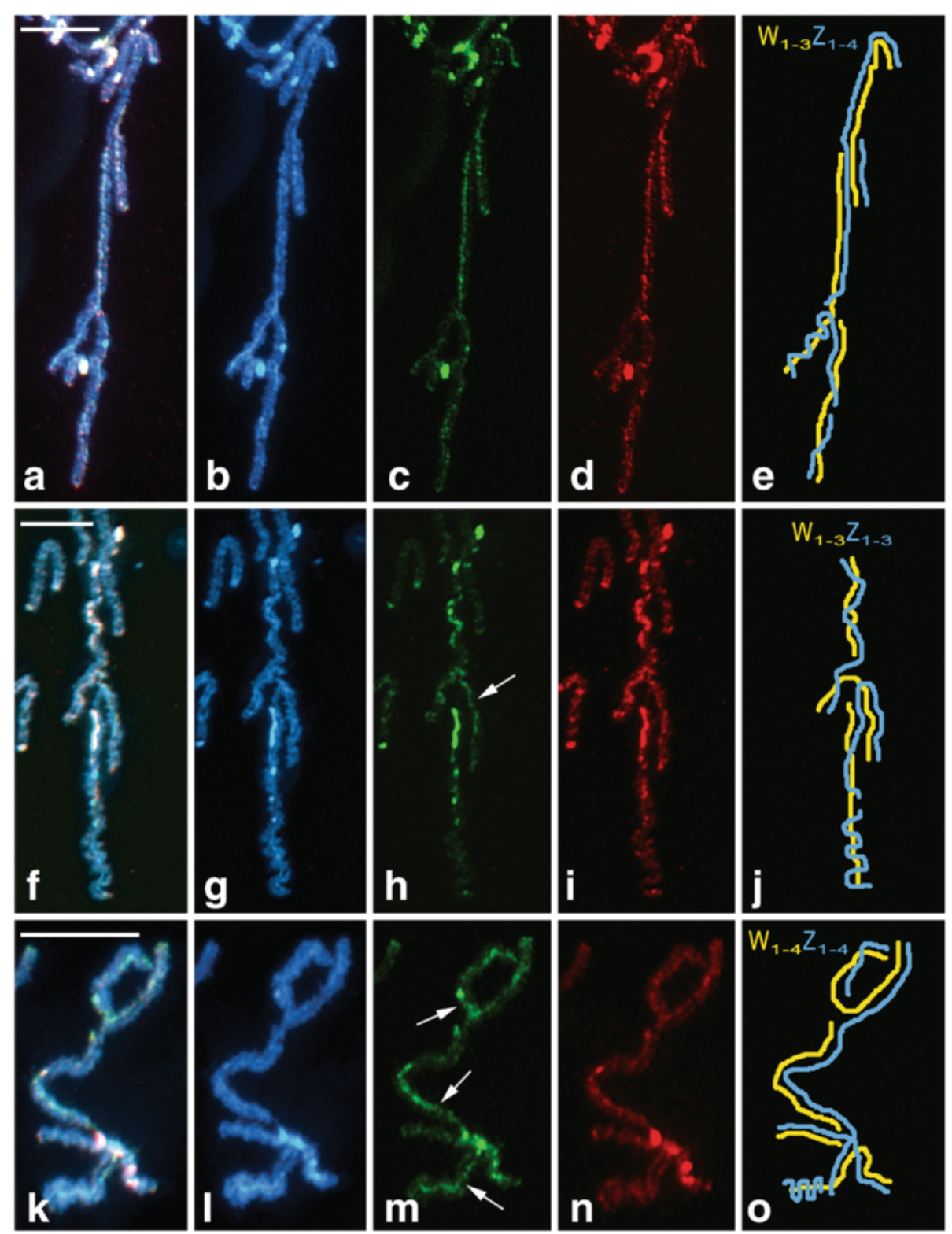

Fig. 6 Comparative genomic hybridization (CGH) in pachytene oocytes of Leptidea juvernica (a-e), L. sinapis (f-j) and L. reali (k-o). Female-derived genomic probes were labelled with fluorescein-12-dUTP (green), male-derived genomic probes were labelled with Cy3-dUTP (red) and chromosomes were counterstained with DAPI (blue). Figures $(\mathbf{a}-\mathbf{e}),(\mathbf{f}-\mathbf{j})$ and $(\mathbf{k}-\mathbf{o})$ show detailed analyses of sex chromosome multivalents $W_{1-n} Z_{1-n}:(\mathbf{a}, \mathbf{f}, \mathbf{k})$ merged images of both genomic probes and DAPI staining; (b, $\mathbf{g}, \mathbf{l})$ DAPI images; $(\mathbf{c}, \mathbf{h}, \mathbf{m})$ female genomic probes; arrows indicate W-chromosome segments with female-specific hybridization pattern; $(\mathbf{d}, \mathbf{i}, \mathbf{n})$ male genomic probes; $(\mathbf{e}, \mathbf{j}, \mathbf{o})$ schematic drawings of the sex chromosome multivalents.

Scale bars $=10 \mu \mathrm{m}$

The karyotypes of Leptidea species also differed in the number and location of two cytogenetic markers used in this study, clusters of rRNA genes (major rDNA) and H3 histone genes. In $L$. reali, the species with the lowest chromosome number, all larvae showed consistent results with a single terminal rDNA cluster and an interstitial cluster of $\mathrm{H} 3$ genes per haploid genome. The highest variability in the number and position of both cytogenetic markers was observed within and among the offspring of individual L. sinapis females. In L. juvernica, the number and location of $\mathrm{H} 3$ histone genes differed in the progeny of individual females, while one rDNA cluster was always located in the middle of one pachytene bivalent. Except for $L$. reali, both cytogenetic markers often marked multivalents. Interspecific differences as well as intrapopulation variability in rDNA distribution 
in L. sinapis are in agreement with the hypothesis on dynamic evolution of genes for major RNAs in Lepidoptera [51]. However, the differences in the number and location of $\mathrm{H} 3$ histone genes in L. sinapis and especially L. juvernica are rather surprising, since this marker shows a highly conserved pattern in the lepidopteran family Tortricidae [52] and other insect groups, such as the Acrididae grasshoppers [53] and Scarabaeinae beetles [54]. Our results thus support the previously reported intraspecific variability in the karyotype of L. sinapis [39] and highlight the ongoing explosive karyotype evolution in all three Leptidea species.

To further explore Leptidea karyotypes and to identify their sex chromosomes we performed GISH combined with tel-FISH. In pachytene nuclei of lepidopteran females, the WZ bivalent is usually easily discernible with GISH by deep staining of the W chromosome thread with the fluorescently labelled female gDNA probe $[43,45,55]$. In all three Leptidea species, the analysis revealed unique sex chromosome systems with the following constitutions: $\mathrm{W}_{1} \mathrm{~W}_{2} \mathrm{~W}_{3} \mathrm{Z}_{1} \mathrm{Z}_{2} \mathrm{Z}_{3} \mathrm{Z}_{4}$ in L. juvernica, $\mathrm{W}_{1} \mathrm{~W}_{2} \mathrm{~W}_{3} \mathrm{Z}_{1} \mathrm{Z}_{2} \mathrm{Z}_{3}$ in L. sinapis and $\mathrm{W}_{1} \mathrm{~W}_{2} \mathrm{~W}_{3} \mathrm{~W}_{4} \mathrm{Z}_{1} \mathrm{Z}_{2} \mathrm{Z}_{3} \mathrm{Z}_{4}$ in $L$. reali. The constitution seemed to be stable in the progenies of individual females. Multiple sex chromosome systems have been documented in mammals $[56,57]$, fish $[58,59]$ and spiders $[60,61]$. However, the majority of moths and butterflies show a WZ/ZZ sex chromosome system. Multiple sex chromosomes have so far been found only in seven genera and only in two different constitutions, either with $\mathrm{W}_{1} \mathrm{~W}_{2} \mathrm{Z}$ or $\mathrm{WZ}_{1} \mathrm{Z}_{2}$ trivalents in females [46]. Thus, the sex chromosome constitutions observed in Leptidea stand out for its complexity and the number of chromosomes involved in the multivalent in meiosis. In addition, this is the first case of multiple sex chromosomes in butterflies (Papilionoidea). Besides sex chromosomes, the gDNA probes also highlighted heterochromatin blocks abundantly present in the karyotypes of all three studied species. In Lepidoptera, heterochromatin is usually confined to the NOR containing rDNA repeats $[51,52]$ and to the W chromosome [44, 62]. So far, similar heterochromatin blocks have been found only in subtelomeric regions of the white butterfly Pieris brassicae (Pieridae) [51] and on chromosome 24 of Bombyx mori [63]. In Leptidea, however, heterochromatin was evenly distributed throughout the whole genome. Such distribution suggests the preponderance of tandemly arranged repetitive sequences in Leptidea genomes in comparison with other lepidopteran species, which could ultimately contribute to the remarkable karyotype diversity in this group.

In addition to the different sex chromosome constitution, the three Leptidea species also differed in their overall genomic hybridization pattern. In $L$. sinapis and L. juvernica, all W chromosomes were at least partially differentiated by strong binding of fluorescently labelled
gDNA probes with GISH and CGH, indicating the accumulation of repetitive sequences and transposable elements in the W chromosomes (cf. [64]). In L. reali, one of the W chromosomes was not highlighted by any gDNA probe. This $\mathrm{W}$ chromosome probably represents an evolutionarily young element, which did not have sufficient time to differentiate. Individual $\mathrm{Z}$ chromosomes involved in multivalents thus probably correspond to the so-called evolutionary strata, which were also reported in mammals, birds and plants [65-69]. Moreover, similar hybridization patterns of male and female genomic probes in CGH experiments suggest a predominance of common repetitive sequences and transposons and a low amount of $\mathrm{W}$-specific sequences on the $\mathrm{W}$ chromosomes of $L$. sinapis and L. juvernica. On the contrary, the preferential binding of the female-derived genomic probe to three of the four $\mathrm{W}$ chromosomes in $L$. reali suggest a relatively high proportion of W-specific sequences.

Observed differences in chromosome numbers and location of the major rDNA and H3 histone gene clusters as well as the existence of complex sex chromosome systems corroborate the role of chromosomal rearrangements in the speciation of the closely related Leptidea species examined in this study. It has been shown that chromosomal rearrangements have a potential to limit gene flow and thus facilitate the development and maintenance of reproductive isolation by means of suppressed recombination [16-18]. The majority of studies on the effects of chromosome fusion and fission on speciation have been done in organisms with monocentric chromosomes that exhibit Robertsonian translocations, i.e. centric fusions [70-72]. These studies confirmed the role of chromosomal fusions in reducing the frequency of recombination. The variation in chromosome size and number is explained as a result of frequent fusion and fission events also in taxa with holokinetic chromosomes $[39,73]$, in which kinetochores are distributed along most of the poleward facing chromosome surface [74]. In this case, fusion is likely to behave as a stable centric fusion and fission leads to viable chromosomal fragments that are normally inherited during meiosis [75, 76]. A recent study stressed the effect of chromosome fusion on the recombination rate in holokinetics [77]. Moreover, studies in sedges (Carex, Cyperaceae) proved that fusion and fission of holokinetic chromosomes also have the potential to restrict gene flow and lead to divergence and eventually speciation [78].

The complex sex chromosome constitution revealed in this study is likely another factor involved in the speciation of Leptidea butterflies. It has been proposed that the $\mathrm{Z}$ sex chromosome could play a disproportionately larger role in adaptive evolution compared to autosomes [79-81]. This so-called 'large- $Z$ effect' was reported in both birds $[79,81-83]$ and Lepidoptera $([5,84]$, the two 
largest taxa with female heterogamety. Furthermore, detailed studies on the neo-sex chromosome evolution in geographic populations of S. cynthia and leaf-rollers of the family Tortricidae suggest that sex chromosomal rearrangements play a major role in the formation of reproductive barriers between populations and contribute to radiation in some lepidopteran taxa, respectively [21, 85]. In Leptidea, the multiple sex chromosome system most likely originated by complex translocations between the ancestral WZ pair and several autosomes, which increased the number of sex-linked genes and thus accelerated the accumulation of genetic incompatibilities among populations. This is supported by the intraspecific stability of their multiple sex chromosomes systems, which is in stark contrast to the evolutionary dynamics of their autosomes. Another signal of reinforcement could be the fact that the most recently diverged sister species, $L$. sinapis and $L$. reali, display not only the largest differences in chromosome numbers in sympatry $[38,39]$ but also the most different sex determination system (as shown in this study).

\section{Conclusions}

To conclude, we confirmed significant differences in the number and structure of chromosomes within and among closely related wood white butterflies. We showed that the distribution of cytogenetic markers differs remarkably even in the offspring of individual females, probably due to irregular segregation of multivalents in meiosis. Our results suggest rapid karyotype evolution in the examined Leptidea species and stress the role of chromosomal rearrangements, especially multiple chromosome fusions and fissions, in their speciation. Remarkably, all three Leptidea species have complex sex chromosome systems with 3$4 \mathrm{~W}$ and 3-4 Z chromosomes. Such sex chromosome constitutions are unique among Lepidoptera and should be counted as an additional factor potentially contributing to the speciation process in Leptidea butterflies. Taken together, these findings add to accumulating evidence on the important role of chromosomal rearrangements in speciation and also point to the relevance of multiple sex chromosomes in species divergence and the formation of reproductive barriers.

\section{Methods}

\section{Sample collecting}

Fresh adult specimens of Leptidea juvernica and L. sinapis were collected in the Czech Republic, namely in the surroundings of České Budějovice and near Havraníky village in the Podyjí National Park in South Moravia, respectively. The third species, $L$. reali, was collected in the Montseny area near Barcelona, Spain. In the laboratory, fertilized females were kept in plastic containers to lay eggs. The bodies of all collected individuals were then placed into $1.5 \mathrm{ml}$ Eppendorf tubes, frozen in liquid nitrogen and stored at $-80{ }^{\circ} \mathrm{C}$ until DNA extraction, except for their genitalia which were immediately used for morphometric analysis. Hatched larvae were reared on corresponding host plants, Lathyrus pratensis for L. juvernica and $L$. reali and Securigera varia for $L$. sinapis, at room temperature and normal day/night regime.

\section{Genitalia preparation and morphometric analysis}

Male and female genitalia were dissected in a physiological solution and inspected under a stereomicroscope. Lengths of two elements of the male genitalia, phallus and saccus and one element of the female genitalia, ductus bursae, were measured. These diagnostic characters discriminate $L$. sinapis from the other two species, $L$. juvernica and $L$. reali, which cannot be reliably distinguished from each other based on morphological features (Fig. 1; [38]).

\section{Specimen sequencing}

Genomic DNA (gDNA) was extracted from legs of every female that gave progeny used in cytogenetic studies, i.e. from $6 L$. sinapis, $6 L$. reali and $4 L$. juvernica females, using the NucleoSpin Tissue XS kit (Macherey-Nagel, Düren, Germany) according to the supplier's protocol. To confirm the taxonomic determination of the examined specimens, molecular phylogenetic trees were constructed using one mitochondrial gene, cytochrome $c$ oxidase subunit $1(C O I)$ and one nuclear marker, the internal transcribed spacer 2 (ITS2). For each individual, a partial sequence of both markers was amplified by polymerase chain reaction $(\mathrm{PCR})$ using two pairs of primers: for COI (658 bp) LepF1 (5' -ATTCAACCAATCATAAAGATA TTGG-3') and LepR1 (5'-TAAACTTCTGGATGTCCAA AAAATCA-3'); for ITS2 (684 bp) ITS3 (5'-GCATCGATG AAGAACGCAGC-3') and ITS4 (5'-TCCTCCGCTTATTG ATATGC-3') [38].

PCR was carried out in $25-\mu \mathrm{L}$ reaction volumes containing $1 \times$ Ex Taq buffer (TaKaRa, Otsu, Japan), $0.2 \mathrm{mM}$ dNTP mix, $5 \mu \mathrm{mol}$ of each primer, 0.25 U Ex Taq Hot Start DNA polymerase (TaKaRa) and about $100 \mathrm{ng}$ of template gDNA. The typical thermal cycling profile for COI consisted of an initial denaturation period of $5 \mathrm{~min}$ at $95{ }^{\circ} \mathrm{C}$ followed by 30 cycles of $30 \mathrm{~s}$ at $95{ }^{\circ} \mathrm{C}, 1 \mathrm{~min}$ at $44{ }^{\circ} \mathrm{C}$ and $1 \mathrm{~min}$ at $72{ }^{\circ} \mathrm{C}$ and by a final extension step of $7 \mathrm{~min}$ at $72{ }^{\circ} \mathrm{C}$. The profile was similar for the nuclear marker ITS2 except for the annealing temperature, which was $50{ }^{\circ} \mathrm{C}$. PCR products were purified using a Wizard SV Gel and PCR Clean-Up System (Promega, Madison, WI, USA) and sequenced using BigDye ${ }^{\circ}$ Terminator v3.1 Cycle Sequencing Kit (Applied Biosystems, Foster City, CA, USA). 


\section{Phylogenetic analysis}

Sequences were edited and aligned using GENEIOUS PRO 4.7.5 created by Biomatters (http://www.geneious.$\mathrm{com} /$ ). Our sequences were combined with all available COI and ITS2 haplotypes of Leptidea sinapis, L. reali and $L$. juvernica identified in a previous study [41] and with sequences of L. morsei, L. amurensis, L. lactea and $L$. duponcheli that were used as outgroup (Additional file 5: Table S1). Thus, the final COI alignment contained 69 nucleotide sequences and was $658 \mathrm{bp}$ long, while the ITS2 alignment involved 28 sequences and consisted of 684 positions.

To confirm the identification of the examined specimens, neighbor-joining trees [86] were built for COI and ITS2. Both trees were based on $p$-distance [87] and pairwise deletion. Node supports were assessed through 100 bootstrap replicates [88]. The trees were inferred in MEGA6 [89].

\section{Chromosome preparation}

In each Leptidea species, two types of spread chromosome preparations were made from fifth instar male and female larvae. Mitotic chromosomes were obtained from wing imaginal discs characterized by a high mitotic index [52], while meiotic chromosomes were obtained from ovaries and testes. In both cases we used the procedure described in [45]. All preparations were passed through a graded ethanol series $(70 \%, 80 \%$ and $100 \%$, 1 min each) and stored at $-80{ }^{\circ} \mathrm{C}$ until further use.

\section{Preparation of polyploid nuclei}

Malpighian tubules were dissected out from fifth instar larvae of both sexes and adult females in a physiological solution. Removed tubules were fixed in ethanol/chloroform/acetic acid (6:3:1) for 1 minute and stained in $1.5 \%$ lactic acetic orcein. Preparations were inspected under a light microscope for the presence of female specific sex chromatin [44].

\section{FISH with fluorochrome-labelled probes}

For the chromosome counts we used spread chromosome preparations from wing imaginal discs stained by FISH with (TTAGG) ${ }_{n}$ telomeric probes (tel-FISH), which helped us to identify the chromosome ends. The telomeric probes were generated by non-template PCR as described in [90] and labelled by Cy3-dUTP (GE Healthcare, Milwaukee, WI, USA) using a Nick Translation Kit (Abbott Molecular Inc., Des Plaines, IL, USA) with 1 hour incubation at $15{ }^{\circ} \mathrm{C}$. For tel-FISH we followed the procedure described in [55]. The probe cocktail contained $100 \mathrm{ng}$ of Cy3-labelled telomeric probe and $25 \mu \mathrm{g}$ of sonicated salmon sperm DNA (Sigma-Aldrich, St. Louis, MO, USA) in $10 \mu \mathrm{l}$ of $50 \%$ formamide and $10 \%$ dextran sulfate in $2 \times$ SSC.
GISH and CGH were used to identify the sex chromosomes and examine their molecular differentiation [43, 91]. GISH was combined with tel-FISH for better resolution of the sex chromosome constitution [55]. Genomic DNAs for both GISH and CGH experiments were extracted separately from adult Leptidea males and females by standard phenol-chloroform procedure. Male gDNA was also amplified by GenomiPhi HY DNA Amplification Kit (GE Healthcare), thereafter sonicated using a Sonopuls HD 2070 (Bandelin Electric, Berlin, Germany) and used as a competitor DNA [52]. The extracted male gDNA was labelled with Cy3-dUTP (GE Healthcare) and female gDNA with fluorescein-12-dUTP (Invitrogen, Carlsbad, CA, USA) using the Nick Translation Kit with 8 hours incubation at $15^{\circ} \mathrm{C}$.

For GISH combined with tel-FISH the probe cocktail contained fluorescein-labelled female gDNA (300 ng), Cy3-labelled telomeric probe (100 ng), unlabelled sonicated male gDNA $(3 \mu \mathrm{g})$ and sonicated salmon sperm DNA $(25 \mu \mathrm{g})$. The probe cocktail for CGH was similar to GISH, except that it contained Cy3-labelled male gDNA (300 ng) instead of the telomeric probe. The preparations were counterstained with $0.5 \mathrm{mg} / \mathrm{mL}$ DAPI and mounted in antifade based on DABCO (Sigma-Aldrich).

\section{FISH with biotin- and digoxigenin-labelled probes}

Unlabelled $18 \mathrm{~S}$ rDNA probe was generated by PCR from the codling moth (Cydia pomonella) gDNA extracted from adults by standard phenol-chloroform procedure as described in [43]. The probe was labelled with biotin16-dUTP (Roche Diagnostics GmbH, Mannheim, Germany) by nick translation using the Nick Translation Kit with 1 hour and 45 minutes incubation at $15^{\circ} \mathrm{C}$.

Unlabelled $\mathrm{H} 3$ histone probe was obtained by PCR from L. sinapis gDNA. PCR was carried out using degenerate forward (5'-ATGGCNCGTACNAARCARAC-3') and reverse ( $5^{\prime}$-TANGCACGYTCNCGGAT-3') primers and the final PCR product was cloned as described in [52]. The probe was labelled in $25-\mu \mathrm{L}$ PCR reaction containing $1 \times$ Ex Taq buffer, $0.1 \mathrm{mM}$ dATP, dGTP and dCTP, $0.065 \mathrm{mM}$ dTTP, $0.035 \mathrm{mM}$ biotin-16-dUTP, $5 \mu \mathrm{mol}$ of each M-13 universal primers, $0.25 \mathrm{U}$ TaKaRa Ex Taq Hot Start DNA polymerase and about $5 \mathrm{ng}$ of plasmid DNA. The thermal cycle profile consisted of an initial denaturation period of $2 \mathrm{~min}$ at $94{ }^{\circ} \mathrm{C}$ followed by 30 cycles of $30 \mathrm{~s}$ at $94{ }^{\circ} \mathrm{C}, 30 \mathrm{~s}$ at $57{ }^{\circ} \mathrm{C}$ and $1 \mathrm{~min}$ at $72{ }^{\circ} \mathrm{C}$ and a final extension step of $2 \min$ at $72{ }^{\circ} \mathrm{C}$.

In FISH experiments, $18 \mathrm{~S}$ rDNA and $\mathrm{H} 3$ histone probes were combined with telomeric probes. Unlabelled telomeric probe generated by non-template PCR (see above) was labelled with digoxigenin (Roche Diagnostics $\mathrm{GmbH}$ ) using the Nick Translation Kit. The detection of biotin was carried out as described in [43]: the signals were detected with Cy3-conjugated streptavidin (Jackson 
ImmunoRes. Labs. Inc., West Grove, PA, USA), amplified with biotinylated anti-streptavidin (Vector Labs. Inc., Burlingame, CA, USA) and again detected with Cy3-conjugated streptavidin. The detection of digoxigenin was carried out by Fluorescent Antibody Enhancer Set for DIG Detection (Roche Diagnostics GmbH). Like in the above-mentioned FISH experiments, the preparations were counterstained with $0.5 \mu \mathrm{g} / \mathrm{mL}$ DAPI and mounted in the DABCO-based antifade.

\section{Microscopy and image processing}

Preparations from FISH experiments were observed under a Zeiss Axioplan 2 microscope (Carl Zeiss Jena, Germany). Black-and-white images were recorded with a cooled FView CCD camera using AnalySIS software, version 3.2 (Soft Imaging System GmbH, Münster, Germany). In all preparations, images were captured separately for each fluorescent dye, pseudocoloured (light blue for DAPI, green for fluorescein and red for $\mathrm{Cy} 3$ ) and superimposed with Adobe Photoshop, version 7.0.

\section{Additional files}

Additional file 1: Figure S1. Neighbor-joining tree of nuclear ITS2 haplotypes of L. sinapis (grey background), L. reali (orange background) and $L$. juvernica (blue background). Specimens sequenced and analysed in this study are indicated by an asterisk. Leptidea amurensis, L. lactea, L. morsei and L. duponcheli were used as outgroup. For the origin of all specimens and GenBank accession numbers, see Additional file 5: Table S1. The scale represents 0.01 substitutions per site. Bootstrap supports (100 replicates) are shown next to the recovered nodes.

Additional file 2: Figure S2. The status of sex chromatin in polyploid nuclei of three Leptidea species. The orcein-stained preparations were made from Malpighian tubule cells of the fifth instar larvae $(\mathbf{a}, \mathbf{c}, \mathbf{d})$ and adult females (b). Black arrows indicate a larger deeply stained heterochromatin body, while arrowheads show smaller bodies. (a) A lower-ploidy female nucleus of L. sinapis with one larger and two smaller bodies. (b) A highly polyploid female nucleus of $L$. sinapis with two bodies, one larger and one smaller. (c) A male nucleus of $L$. reali without distinguishable heterochromatin bodies. (d) A male nucleus of $L$. reali with one smaller body. Scale bar $=10 \mu \mathrm{m}$.

Additional file 3: Figure S3. Analysis of sex chromosome multivalents of pachytene oocytes in Leptidea juvernica $(a-d)$, L. sinapis (e-h) and L. reali (i-I) using FISH with the (TTAGG) $n$ telomeric probe. Hybridization signals of the Cy3-dUTP-labelled telomeric probe (red) indicate chromosome ends. Chromosomes were counterstained with DAPI (blue). Figures $(\mathbf{a}-\mathbf{d}),(\mathbf{e}-\mathbf{h})$ and $(\mathbf{i}-\mathbf{l})$ show sex chromosome multivalents $\mathrm{W}_{1-n} \mathrm{Z}_{1-n}$ : $(\mathbf{a}, \mathbf{e}, \mathbf{i})$ merged images of the $(T \mathrm{TAGG})_{n}$ telomeric probe and DAPI staining; $(\mathbf{b}, \mathbf{f}, \mathbf{j})$ DAPI images; note DAPI-highlighted heterochromatic segments of the W chromosomes; (c, $\mathbf{g}, \mathbf{k}$ ) hybridization pattern of the (TTAGG) telomeric probe; $(\mathbf{d}, \mathbf{h}, \mathbf{l})$ schematic drawings of the sex chromosome multivalents; yellow dots indicate the ends of individual chromosomes involved in the multivalents. Scale bar $=10 \mu \mathrm{m}$.

Additional file 4: Figure S4. Comparison of interphase nuclei sizes in three Leptidea species. The $y$-axis shows the number of pixels. Micrographs of interphase nuclei were taken from DAPI-stained spread preparations of wing discs from three different larvae of each Leptidea species, using the same resolution. In these micrographs, we measured the area of 144 nuclei of $L$. juvernica, 154 nuclei of $L$. reali and 130 nuclei of $L$. sinapis. The measurements were carried out using the software JMicroVision v1.2.7 [Roduit N: JMicroVision: Image analysis toolbox for measuring and quantifying components of high-definition images. Version 1.2.7. http://www.jmicrovision.com (accessed 27 March 2015)]. Calibration was performed using an image resolution so that the area of each nucleus was measured in pixels. The average size of nuclei was calculated for each species independently and then compared between species by one-way ANOVA using the software Statistica for Windows, version 8.0 (StatSoft, Inc., Tulsa, OK, USA). The comparison of interphase nuclei revealed no statistically significant between-species differences in their size $\left(F_{(2,9)}=\right.$ $0.6782 ; P=0.5425)$. The mean $( \pm$ S.E.) area of interphase nuclei was $22434 \pm$ 2296 pixels for $L$. juvernica, $19781 \pm 1965$ pixels for L. reali and $19835 \pm$ 1021 pixels for $L$. sinapis.

Additional file 5: Table S1. List of specimens included in phylogenetic analyses. Sequences obtained in this study are in blue, the other sequences were downloaded from GenBank and are representative for all the $\mathrm{CO}$ and ITS2 haplotypes of Leptidea sinapis, L. reali and L. juvernica identified in a previous study [41]. The haplotype numbers correspond to those in [41].

\section{Abbreviations}

CGH: Comparative genomic hybridization; COl: Cytochrome c oxidase subunit 1; FISH: Fluorescence in situ hybridization; gDNA: Genomic DNA; GISH: Genomic in situ hybridization; H3: Histone H3; ITS2: Internal transcribed spacer 2; MI: Meiotic metaphase I; NOR: Nucleolar organizer region; PCR: Polymerase chain reaction; rDNA: Ribosomal DNA; rRNA: Ribosomal RNA; tel-FISH: Fluorescence in situ hybridization with $(T T A G G)_{n}$ telomeric probe.

\section{Competing interests}

The authors declare that they have no competing interests.

\section{Authors' contributions}

KS performed first cytogenetic analyses and obtained preliminary data in Leptidea juvernica and L. sinapis. JŠ and FM conceived and designed the experiments and collected population samples of L. juvernica and L. sinapis. RV collected and supplied samples of the Spanish population of L. reali. JŠ performed most experiments and analysed the data. AV and PN participated in the preparation of FISH probes, some FISH experiments and isolation of genes for molecular analyses. VD and RV performed phylogenetic analyses. J̌́, PN and FM interpreted the data and drafted the manuscript. All authors read and approved the final manuscript.

\section{Acknowledgements}

Our thanks go to Marie Korchová for excellent technical assistance and Leonela Carabajal Paladino for help with statistical analysis. This research was funded by Grant 14-22765S of the Czech Science Foundation, Grant IAA600960925 of the Grant Agency of The Czech Academy of Sciences, Grant 063/2012/P of the Grant Agency of the University of South Bohemia and Grant CGL2013-48277-P from the Spanish Ministerio de Economía y Competitividad. JŠ and AV were supported by Grant 052/2013/P of the Grant Agency of the University of South Bohemia, VD by a Marie Curie International Outgoing Fellowship within the 7th European Community Framework Programme (project no. 625997), PN by Grant 14-35819P of the Czech Science Foundation and KS by JSPS 23380030 grant and JSPS Excellent Young Researchers Overseas Visit Program (21-7147).

\section{Author details}

'Institute of Entomology, Biology Centre CAS, 37005 České Budějovice, Czech Republic. ${ }^{2}$ Faculty of Science, University of South Bohemia, 37005 České Budějovice, Czech Republic. ${ }^{3}$ Biodiversity Institute of Ontario, University of Guelph, N1G 2W1 Guelph, ON, Canada. ${ }^{4}$ Institut de Biologia Evolutiva (CSIC-Universitat Pompeu-Fabra), 08003 Barcelona, Spain.

${ }^{5}$ Laboratory of Applied Entomology, Faculty of Agriculture, Iwate University, Morioka 020-8550, Japan.

Received: 29 December 2014 Accepted: 7 May 2015 Published online: 19 May 2015

\section{References}

1. van Nieukerken EJ, Kaila L, Kitching IJ, Kristensen NP, Lees DC, Minet J, et al. Order Lepidoptera Linnaeus, 1758. In Animal Biodiversity: An Outline of Higher-level Classification and Survey of Taxonomic Richness. Edited by Zhang ZQ. Zootaxa. 2011;3148:212-21.

2. Brown KS. The biology of Heliconius and related genera. Annu Rev Entomol. 1981;26:427-56. 
3. Sheppard PM, Turner JRG, Brown KS, Benson WW, Singer MC. Genetics and the evolution of muellerian mimicry in Heliconius butterflies. Philos Trans $\mathrm{R}$ Soc Lond B. 1985;308:433-610.

4. Mallet J, Joron M. Evolution of diversity in warning color and mimicry: polymorphism, shifting balance and speciation. Annu Rev Ecol Syst. 1999;30:201-33.

5. Jiggins CD, Linares M, Naisbit RE, Salazar C, Yang ZH, Mallet J. Sex-linked hybrid sterility in a butterfly. Evolution. 2001;55:1631-8.

6. Kronforst MR, Kapan DD, Gilbert LE. Parallel genetic architecture of parallel adaptive radiations in mimetic Heliconius butterflies. Genetics. 2006;174:535-9.

7. Jiggins CD, Naisbit RE, Coe RL, Mallet J. Reproductive isolation caused by colour pattern mimicry. Nature. 2001;411:302-5.

8. Scriber JM, Hagen RH, Lederhouse RC. Genetics of mimicry in the tiger swallowtail butterflies, Papilio glaucus and P. canadensis (Lepidoptera: Papilionidae). Evolution. 1996:50:222-36.

9. Kunte K, Shea C, Aardema ML, Scriber JM, Juenger TE, Gilbert LE, et al. Sex chromosome mosaicism and hybrid speciation among tiger swallowtail butterflies. PLoS Genet. 2011;7, e1002274.

10. Zhang W, Kunte K, Kronforst MR. Genome-wide characterization of adaptation and speciation in tiger swallowtail butterflies using de novo transcriptome assemblies. Genome Biol Evol. 2013;5:1233-45.

11. Ando T, Inomata SI, Yamamoto M. Lepidopteran sex pheromones. Top Curr Chem. 2004;239:51-96.

12. Dopman EB, Robbins PS, Seaman A. Components of reproductive isolation between North American pheromone strains of the European corn borer. Evolution. 2010;64:881-902

13. Olsson SB, Kesevan S, Groot AT, Dekker T, Heckel DG, Hansson BS. Ostrinia revisited: Evidence for sex linkage in European corn borer Ostrinia nubilalis (Hübner) pheromone reception. BMC Evol Biol. 2010;10:285.

14. Leary GP, Allen JE, Bunger PL, Luginbill JB, Linn Jr CE, Macallister IE, et al. Single mutation to a sex pheromone receptor provides adaptive specificity between closely related moth species. Proc Natl Acad Sci U S A. 2012;109:14081-6.

15. Lukhtanov VA, Kandul NP, Plotkin JB, Dantchenko AV, Haig D, Pierce NE. Reinforcement of pre-zygotic isolation and karyotype evolution in Agrodiaetus butterflies. Nature. 2005:436:385-9.

16. Noor MA, Grams KL, Bertucci LA, Reiland J. Chromosomal inversions and the reproductive isolation of species. Proc Natl Acad Sci U S A. 2001;98:12084-8.

17. Rieseberg LH. Chromosomal rearrangements and speciation. Trends Ecol Evol. 2001;16:351-8.

18. Faria R, Navarro A. Chromosomal speciation revisited: rearranging theory with pieces of evidence. Trends Ecol Evol. 2010;25:660-9.

19. Sperling FAH. Sex-linked genes and species-differences in Lepidoptera. Can Entomol. 1994;126:807-18.

20. Prowell DP. Sex Linkage and Speciation in Lepidoptera. In: Howard DJ, Berlocher SH, editors. Endless Forms: Species and Speciation. New York: Oxford University Press; 1998. p. 309-19.

21. Yoshido A, Sahara K, Marec F, Matsuda Y. Step-by-step evolution of neo-sex chromosomes in geographical populations of wild silkmoths, Samia cynthia ssp. Heredity. 2011;106:614-24.

22. Yoshido A, Šíchová J, Kubíčková S, Marec F, Sahara K. Rapid turnover of the W chromosome in geographical populations of wild silkmoths, Samia cynthia ssp. Chromosome Res. 2013;21:149-64.

23. Carpenter JE, Bloem S, Marec F. Inherited Sterility in Insects. In: Dyck VA, Hendrichs J, Robinson AS, editors. Sterile Insect Technique. Principles and Practice in Area-Wide Integrated Pest Management. Dordrecht: Springer; 2005. p. 115-46.

24. Pringle EG, Baxter SW, Webster CL, Papanicolaou A, Lee SF, Jiggins CD. Synteny and chromosome evolution in the Lepidoptera: Evidence from mapping in Heliconius melpomene. Genetics. 2007:177:417-26.

25. Beldade P, Saenko SV, Pul N, Long AD. A gene-based linkage map for Bicyclus anynana butterflies allows for a comprehensive analysis of synteny with the lepidopteran reference genome. PLoS Genet. 2009;5, e1000366.

26. Yasukochi Y, Tanaka-Okuyama M, Shibata F, Yoshido A, Marec F, Wu C, et al. Extensive conserved synteny of genes between the karyotypes of Manduca sexta and Bombyx mori revealed by BAC-FISH mapping. PLoS ONE. 2009;4, e7465.

27. d'Alençon E, Sezutsu H, Legeai F, Permal E, Bernard-Samain S, Gimenez S, et al. Extensive synteny conservation of holocentric chromosomes in Lepidoptera despite high rates of local genome rearrangements. Proc Natl Acad Sci U S A. 2010;107:7680-5.
28. Baxter SW, Davey JW, Johnston JS, Shelton AM, Heckel DG, Jiggins CD, et al. Linkage mapping and comparative genomics using next-generation RAD sequencing of a non-model organism. PLoS ONE. 2011;6, e19315.

29. Sahara K, Yoshido A, Shibata F, Fujikawa-Kojima N, Okabe T, TanakaOkuyama M, et al. FISH identification of Helicoverpa armigera and Mamestra brassicae chromosomes by BAC and fosmid probes. Insect Biochem Mol Biol. 2013:43:644-53.

30. Van't Hof AE, Nguyen P, Dalíková M, Edmonds N, Marec F, Saccheri IJ. Linkage map of the peppered moth, Biston betularia (Lepidoptera, Geometridae): a model of industrial melanism. Heredity. 2013;110:283-95.

31. Suomalainen E. Chromosome evolution in the Lepidoptera. Chromosomes Today. 1969;2:132-8.

32. Ahola $V$, Lehtonen $R$, Somervuo $P$, Salmela $L$, Koskinen $P$, Rastas $P$, et al. The Glanville fritillary genome retains an ancient karyotype and reveals selective chromosomal fusions in Lepidoptera. Nat Commun. 2014;5:4737.

33. Robinson R. Lepidoptera Genetics. Oxford: Pergamon Press; 1971.

34. De Prins J, Saitoh K. Karyology and Sex Determination. In: Kristensen NP, editor. Lepidoptera, Moths and Butterflies: Morphology, Physiology and Development. Berlin: Walter de Gruyter; 2003. p. 449-68.

35. Kandul NP, Lukhtanov VA, Dantchenko DA, Coleman JWS, Sekercioglu C, Haig D, et al. Phylogeny of Agrodiaetus Hübner 1822 (Lepidoptera: Lycaenidae) inferred from mtDNA sequences of $\mathrm{CO}$ and COll and nuclear sequences of EF1- a: karyotype diversification and species radiation. Syst Biol. 2004;53:278-98.

36. de Lesse $\mathrm{H}$. Les nombres de chromosomes dans le groupe de Lysandra argester et leur incidence sur la taxonomie. Bull Soc Entomol Fr. 1970;75:64-8.

37. Lukhtanov VA, Danchenko AD. Principles of the highly ordered arrangement of metaphase I bivalents in spermatocytes of Agrodiaetus (Insecta, Lepidoptera). Chromosome Res. 2002;10:5-20.

38. Dincă V, Lukhtanov VA, Talavera G, Vila R. Unexpected layers of cryptic diversity in wood white Leptidea butterflies. Nat Commun. 2011;2:324.

39. Lukhtanov VA, Dincă V, Talavera G, Vila R. Unprecedented within-species chromosome number cline in the Wood White butterfly Leptidea sinapis and its significance for karyotype evolution and speciation. BMC Evol Biol. 2011;11:109

40. Maeki K. On the cytotaxonomical relationship in Leptidea (LepidopteraRhopalocera). Jpn J Genet. 1958;33:283-5.

41. Dincă V, Wiklund C, Lukhtanov VA, Kodandaramaiah U, Norén K, Dapporto L, et al. Reproductive isolation and patterns of genetic differentiation in a cryptic butterfly species complex. J Evol Biol. 2013;26:2095-106.

42. Marec F, Traut W. Sex chromosome pairing and sex chromatin bodies in W-Z translocation strains of Ephestia kuehniella (Lepidoptera). Genome. 1994;37:426-35.

43. Fuková I, Nguyen P, Marec F. Codling moth cytogenetics: karyotype, chromosomal location of rDNA and molecular differentiation of sex chromosomes. Genome. 2005;48:1083-92.

44. Traut W, Marec F. Sex chromatin in Lepidoptera. Q Rev Biol. 1996;71:239-56.

45. Mediouni J, Fuková I, Frydrychová R, Dhouibi MH, Marec F. Karyotype, sex chromatin and sex chromosome differentiation in the carob moth, Ectomyelois ceratoniae (Lepidoptera: Pyralidae). Caryologia. 2004;57:184-94.

46. Traut W, Sahara K, Marec F. Sex chromosomes and sex determination in Lepidoptera. Sex Dev. 2007;1:332-46.

47. Traut W, Weith A, Traut G. Structural mutants of the W chromosome in Ephestia (Insecta, Lepidoptera). Genetica. 1986;70:69-79.

48. Colombo PC. Cytogeography of three parallel Robertsonian polymorphisms in the water-hyacinth grasshopper, Cornops aquaticum (Orthoptera: Acrididae). Eur J Entomol. 2008;105:59-64.

49. Castiglia R, Annesi F, Capanna E. Geographical pattern of genetic variation in the Robertsonian system of Mus musculus domesticus in central Italy. Biol J Linn Soc Lond. 2005:84:395-405.

50. White TA, Bordewich M, Searle JB. A network approach to study karyotypic evolution: the chromosomal races of the common shrew (Sorex araneus) and house mouse (Mus musculus) as model systems. Syst Biol. 2010;59:262-76.

51. Nguyen P, Sahara K, Yoshido A, Marec F. Evolutionary dynamics of rDNA clusters on chromosomes of moths and butterflies (Lepidoptera). Genetica. 2010:138:343-54

52. Šíchová J, Nguyen P, Dalíková M, Marec F. Chromosomal evolution in tortricid moths: conserved karyotypes with diverged features. PLoS ONE. 2013;8, e64520.

53. Cabrero J, López-León MD, Teruel M, Camacho JPM. Chromosome mapping of $\mathrm{H} 3$ and $\mathrm{H} 4$ histone gene clusters in 35 species of acridid grasshoppers. Chromosome Res. 2009;17:397-404 
54. Cabral-de-Mello DC, Oliveira SG, de Moura RC, Martins C. Chromosomal organization of the $18 \mathrm{~S}$ and $5 \mathrm{~S}$ rRNAs and histone $\mathrm{H} 3$ genes in Scarabaeinae coleopterans: insights into the evolutionary dynamics of multigene families and heterochromatin. BMC Genet. 2011;12:88.

55. Yoshido A, Marec F, Sahara K. Resolution of sex chromosome constitution by genomic in situ hybridization and fluorescence in situ hybridization with $(\text { TTAGG })_{n}$ telomeric probe in some species of Lepidoptera. Chromosoma. 2005;114:193-202

56. Rens W, Grützner F, O'Brien PCM, Fairclough HF, Graves JAM, FergusonSmith MA. Resolution and evolution of the duck-billed platypus karyotype with an $X_{1} Y_{1} X_{2} Y_{2} X_{3} Y_{3} X_{4} Y_{4} X_{5} Y_{5}$ male sex chromosome constitution. Proc Natl Acad Sci U S A. 2004;101:16257-61.

57. Veyrunes F, Waters PD, Miethke P, Rens W, McMillan D, Alsop AE, et al. Bird-like sex chromosomes of platypus imply recent origin of mammal sex chromosomes. Genome Res. 2008;18:965-73.

58. Cioffi MB, Sánchez A, Marchal JA, Kosyakova N, Liehr T, Trifonov V, et al. Cross-species chromosome painting tracks the independent origin of multiple sex chromosomes in two cofamiliar Erythrinidae fishes. BMC Evol Biol. 2011;11:186

59. Blanco DR, Vicari MR, Lui RL, Artoni RF, de Almeida MC, Traldi JB, et al. Origin of the $X_{1} X_{1} X_{2} X_{2} / X_{1} X_{2} Y$ sex chromosome system of Harttia punctata (Siluriformes, Loricariidae) inferred from chromosome painting and FISH with ribosomal DNA markers. Genetica. 2014;142:119-26.

60. Král J. Evolution of multiple sex chromosomes in the spider genus Malthonica (Araneae: Agelenidae) indicates unique structure of the spider sex chromosome systems. Chromosome Res. 2007;15:863-79.

61. Král J, Korínková T, Forman M, Krkavcová L. Insights into the meiotic behavior and evolution of multiple sex chromosome systems in spiders. Cytogenet Genome Res. 2011;133:43-66

62. Traut W, Marec F. Sex chromosome differentiation in some species of Lepidoptera (Insecta). Chromosome Res. 1997;5:283-91.

63. Yoshido A, Bando H, Yasukochi Y, Sahara K. The Bombyx mori karyotype and the assignment of linkage groups. Genetics. 2005;170:675-85.

64. Sahara K, Marec F, Eickhoff U, Traut W. Moth sex chromatin probed by comparative genomic hybridization (CGH). Genome. 2003;46:339-42.

65. Lahn BT, Page DC. Four evolutionary strata on the human X chromosome. Science. 1999;286:964-7.

66. Bergero $R$, Forrest $A$, Kamau $E$, Charlesworth $D$. Evolutionary strata on the $X$ chromosomes of the dioecious plant Silene latifolia: evidence from new sex-linked genes. Genetics. 2007;75:1945-54.

67. Nam K, Ellegren $\mathrm{H}$. The chicken (Gallus gallus) Z chromosome contains at least three nonlinear evolutionary strata. Genetics. 2008;180:1131-6.

68. Mácha J, Teichmanová R, Sater AK, Wells DE, Tlapáková T, Zimmerman LB, et al. Deep ancestry of mammalian $X$ chromosome revealed by comparison with the basal tetrapod Xenopus tropicalis. BMC Genomics. 2012;13:315.

69. Wang J, Na J-K, Yu Q, Gschwend AR, Han J, Zeng F, et al. Sequencing papaya $X$ and $Y^{h}$ chromosomes reveals molecular basis of incipient sex chromosome evolution. Proc Natl Acad Sci U S A. 2012;109:13710-5.

70. Baker RJ, Bickham JW. Speciation by monobrachial centric fusions. Proc Natl Acad Sci U S A. 1986:83:8245-8.

71. Bidau CJ, Giménez MD, Palmer CL, Searle JB. The effects of Robertsonian fusions on chiasma frequency and distribution in the house mouse (Mus musculus domesticus) from a hybrid zone in northern Scotland. Heredity. 2001;87:305-13.

72. Basset $P$, Yannic $G$, Brünner $H$, Hausser J. Restricted gene flow at specific parts of the shrew genome in chromosomal hybrid zones. Evolution. 2006;60:1718-30.

73. Hipp AL, Rothrock PE, Roalson EH. The evolution of chromosome arrangements in Carex (Cyperaceae). Bot Rev. 2009;75:96-109.

74. Melters DP, Paliulis LV, Korf IF, Chan SWL. Holocentric chromosomes: convergent evolution, meiotic adaptations and genomic analysis. Chromosome Res. 2012;20:579-93.

75. Wrensch DL, Kethley JB, Norton RA. Cytogenetics of Holokinetic Chromosomes and Inverted Meiosis: Keys to the Evolutionary Success of Mites, with Generalization on Eukaryotes. In: Houck MA, editor. Mites: Ecological and Evolutionary Analyses of Life-History Patterns. New York: Chapman \& Hall; 1994. p. 282-343.

76. Marec F, Tothová A, Sahara K, Traut W. Meiotic pairing of sex chromosome fragments and its relation to atypical transmission of a sex-linked marker in Ephestia kuehniella (Insecta: Lepidoptera). Heredity. 2001;87:659-71.
77. Bureš P, Zedek F. Holokinetic drive: centromere drive in chromosomes without centromeres. Evolution. 2014;68:2412-20.

78. Hipp AL, Rothrock PE, Whitkus R, Weber JA. Chromosomes tell half of the story: the correlation between karyotype rearrangements and genetic diversity in sedges, a group with holocentric chromosomes. Mol Ecol. 2010;19:3124-38

79. Sætre GP, Borge T, Lindroos K, Haavie J, Sheldon BC, Primmer C, et al. Sex chromosome evolution and speciation in Ficedula flycatchers. Proc Biol Sci. 2003;270:53-9.

80. Ellegren H. Genomic evidence for large-Z effect. Proc Biol Sci. 2009;276:361-6.

81. Štorchová R, Reif J, Nachman MW. Female heterogamety and speciation: reduced introgression of the $Z$ chromosome between two species of nightingales. Evolution. 2010;64:456-71.

82. Carling MD, Brumfield RT. Haldane's rule in an avian system: using cline theory and divergence population genetics to test for differential introgression of mitochondrial, autosomal and sex-linked loci across the Passerina bunting hybrid zone. Evolution. 2008;62:2600-15.

83. Carling MD, Brumfield RT. Speciation in Passerina buntings: introgression patterns of sex- linked loci identify a candidate gene region for reproductive isolation. Mol Ecol. 2009;18:834-47.

84. Naisbit RE, Jiggins CD, Linares M, Salazar C, Mallet J. Hybrid sterility. Haldane's rule and speciation in Heliconius cydno and H. melpomene. Genetics. 2002;161:1517-26.

85. Nguyen P, Sýkorová M, Šíchová J, Kůta V, Dalíková M, Čapková Frydrychová R, et al. Neo-sex chromosomes and adaptive potential in tortricid pests. Proc Natl Acad Sci U S A. 2013;110:6931-6.

86. Saitou N, Nei M. The neighbor-joining method: a new method for reconstructing phylogenetic trees. Mol Biol Evol. 1987:4:406-25.

87. Nei M, Kumar S. Molecular Evolution and Phylogenetics. New York: Oxford University Press; 2000.

88. Felsenstein J. Confidence limits on phylogenies: an approach using the bootstrap. Evolution. 1985;39:783-91.

89. Tamura K, Stecher G, Peterson D, Filipski A, Kumar S. MEGA6: molecular evolutionary genetics analysis version 6.0. Mol Biol Evol. 2013;30:2725-9.

90. Sahara K, Marec F, Traut W. TTAGG telomeric repeats in chromosomes of some insects and other arthropods. Chromosome Res. 1999;7:449-60.

91. Traut W, Sahara K, Otto TD, Marec F. Molecular differentiation of sex chromosomes probed by comparative genomic hybridization. Chromosoma. 1999:108:173-80.

\section{Submit your next manuscript to BioMed Central and take full advantage of:}

- Convenient online submission

- Thorough peer review

- No space constraints or color figure charges

- Immediate publication on acceptance

- Inclusion in PubMed, CAS, Scopus and Google Scholar

- Research which is freely available for redistribution 